\title{
Comparative Study of Linear and Non-Linear Controls of Three-Phase Shunt Active Filters for Improving the Quality of Electrical Energy
}

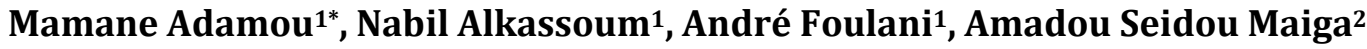 \\ ${ }^{1}$ Department of Physics (FAST), Abdou MOUMOUNI University, Niamey, Niger \\ ${ }^{2}$ Departments of Applied Physics, Gaston Berger University, Saint-Louis, Senegal \\ Email: *mamindi@gmail.com, asmaiga1962@gmail.com
}

How to cite this paper: Adamou, M., Alkassoum, N., Foulani, A. and Maiga, A.S. (2019) Comparative Study of Linear and Non-Linear Controls of Three-Phase Shunt Active Filters for Improving the Quality of Electrical Energy. Energy and Power Engineering, 11, 149-166.

https://doi.org/10.4236/epe.2019.113009

Received: December 1, 2018

Accepted: March 25, 2019

Published: March 28, 2019

Copyright $\odot 2019$ by author(s) and Scientific Research Publishing Inc. This work is licensed under the Creative Commons Attribution International License (CC BY 4.0).

http://creativecommons.org/licenses/by/4.0/

\begin{abstract}
The aim of this work is to comparatively study two types of control of a three-phase shunt active filter (TSAF) in order to realize a system of depollution of electrical networks so as to improve the quality of electrical energy. We used two TSA control models which differ in the method of disturbed currents detection, one linear and the other non-linear. The results show that the non-linear control method, although with high calculation blocks, gives more promising results than the linear control method. When connecting a non-linear load (televisions, lamps, variable speed drives, etc.) directly to the public distribution network, the non-linear nature of the load causes the source current to be deformed due to the presence of harmonic currents and voltages. These harmonics thus generate a high reactive power, and therefore considerable electrical losses in the network. One of the solutions to reduce losses on the electricity grid is to incorporate an electronic circuit called a filter into the electricity grid. This work carried out a comparative study of two types of control of a three-phase shunt active filter (TSAF) in order to carry out a system for cleaning up electricity networks in order to improve the quality of electrical energy. We used two TSA control models that differ in the method of detecting disturbed currents, one linear and the other non-linear. The results show that the non-linear control method, although with high calculation blocks, gives better results than the linear control method.
\end{abstract}

\section{Keywords}

Power Quality, Active Three-Phase Shunt Filter, Non-Linear Control, Linear Control 


\section{Introduction}

Electrical energy is an energy that can be converted into almost all other existing forms of energy and is managed through an electrical network. The quality of electrical energy received by consumers is very essential for the proper functioning of appliances connected to an electrical network. The increasing use of power electronic components on electrical networks is not without major consequences for the latter. Indeed, an alternating voltage source supplying a non-linear load will undergo harmonic current and/or voltage pollution [1]. This harmonic pollution can have consequences on other devices sensitive to the latter which will be supplied by the same source [2]. To overcome this problem, the techniques initially used were the oversizing of electrical equipment in the network and the use of passive power filters [3]. The limits set by the previous solutions to harmonic pollution control will be addressed by active power filters, which constitute one of the modern solutions to power system pollution control [3] [4].

The performance of an active filter depends on the quality of its control. Several control methods have been proposed in the literature [3] [4] [5] [6], but these control methods are linear. As the clean-up devices for electricity networks are non-linear, it was necessary to propose non-linear control methods capable of adapting to them.

For a contribution to the improvement of power quality, in this paper, we propose a comparative study by simulation of the linear and non-linear controls of active power filters case of a three-phase active shunt filter (TSAF).

\section{Electrical Power Quality and TSAF}

The quality of electrical energy is related to any variation in the electrical power supply, resulting in malfunction or damage to users' equipment [5]. These variations in electrical quantities are manifested by voltage dips, overvoltage, harmonic disturbances, imbalances, etc. Figure 1 shows some voltage variations on

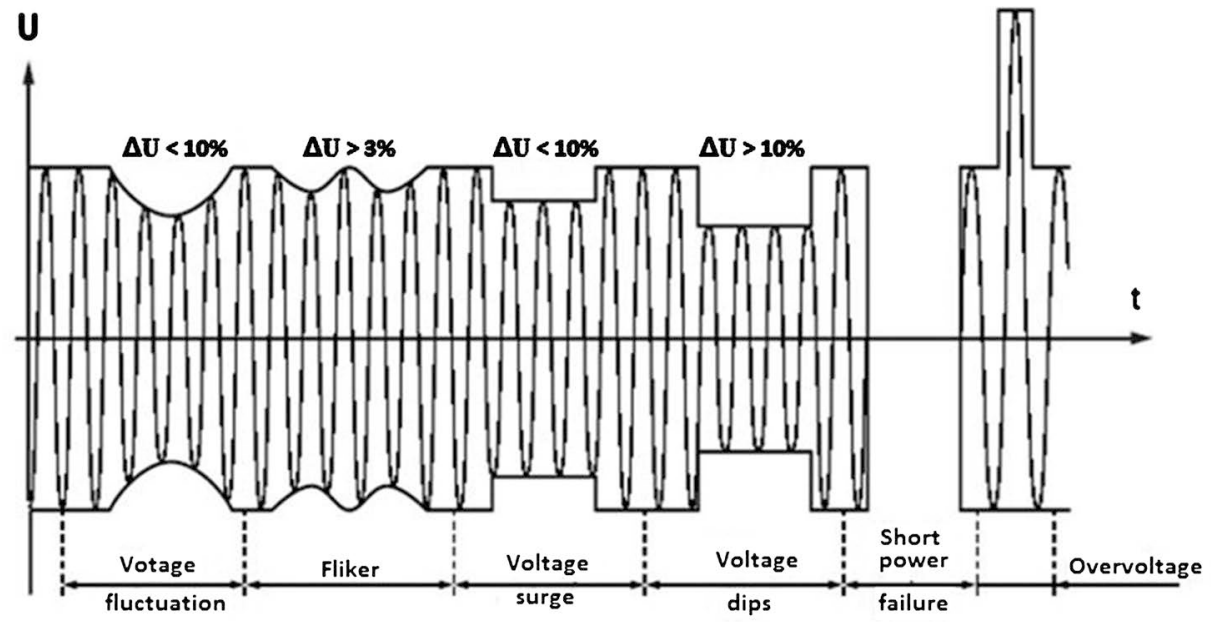

Figure 1. Changes in electrical quantities affecting the quality of electrical energy. 
an electrical network that can affect the quality of electrical power.

In this work we are interested in improving the quality of electrical power in a balanced three-phase network, by compensating harmonic currents using an active three-phase shunt filter (TSAF). Indeed, the disturbances caused by harmonic currents on a network can also affect the voltage through the impedance of the network because the latter is not zero [3].

A three-phase alternating voltage source, supplying a non-linear load, undergoes harmonic pollution that can have consequences on the devices supplied by the same source. The grid voltage and current will no longer be sinusoidal. The role of the active shunt filter is to inject harmonic currents of the same amplitude as the polluting harmonics into the network, but in phase opposition to the latter [7]. By this principle, TSAF is used to improve the quality of electrical energy. This principle is illustrated by the diagram in Figure 2 .

\section{Active Three-Phase Shunt Filter (TSAF)}

\subsection{General Structure of TSAF}

The active shunt filter is a modern device for harmonic and often reactive power compensation. It consists of two main parts: power and control. The principle of the active shunt filter lies in the injection of harmonic currents of the same amplitude as those pollutants but in opposition of phase with them. Compensation being in real time, it is therefore essential to define a good control method [8].

Several models of single-phase or three-phase active filters have been proposed in the literature. Their performance is directly linked either to the nature of the storage element (capacitive or inductive) of the active filter or to the control strategy of the latter [3] [4] [5]. In this document we will study an active shunt filter with capacitive storage; we will then apply a linear then non-linear control.

Figure 1 shows the structure of the study system consisting of a network polluted by a non-linear load and the active shunt compensating filter. The source

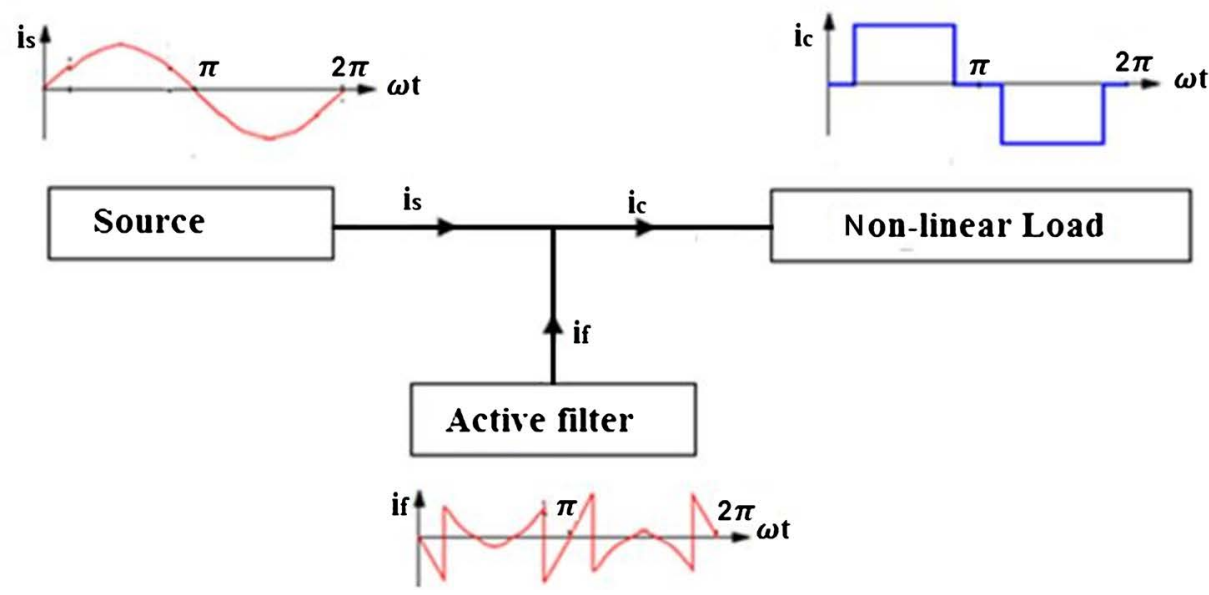

Figure 2. Improvement of the current waveform of a polluted source of the active power shunt filter. 
supplying the system is a balanced three-phase source that can be modeled by the Equations (1).

$$
\left\{\begin{array}{l}
V_{1 N}=U \sqrt{2} \sin (\omega t) \\
V_{2 N}=U \sqrt{2} \sin (\omega t-2 \pi / 3) \\
V_{3 N}=U \sqrt{2} \sin \left(\omega t+\frac{2 \pi}{3}\right)
\end{array}\right.
$$

The non-linear load is a three-phase diode bridge that supplies a resistive load. The active shunt filter is a voltage inverter i.e. with capacitive storage element, it consists of three arms, each of the arms consists of two bidirectional switches (MOSFET, GTO, IGBT). This structure does not allow the simultaneous closing of the semiconductors of the same arm under penalty of short-circuiting the capacitor [3]. However, in some cases, they may both be open (dead time). The continuity of the currents is then ensured by the conduction of one of the diodes of the same arm. In order to couple the active shunt filter to the mains, LF coupling inductors are used; these inductors are also used to attenuate the harmonics due to the switching of the TSAF switches.

\subsection{Modeling the Three-Phase Shunt Active Filter}

To set up the control laws of the active shunt filter, it is necessary to model it according to the system in which this latter is implemented. This modeling will allow, thanks to a regulation or a servo system, to optimize the performances of the system [8]. Thus, it was explained in paragraph 2 that the active shunt filter consists of two main parts i.e. power and control.

The TSAF is controlled in two steps, the first to determine the reference currents and the second using the first to determine the control pulses of the TSAF inverter switches. The opening and closing of the TSAF inverter switches depends on the status of the control signals (S1, S2, S3,), as defined by Equation (4). ([4] [9]):

$$
\begin{aligned}
& \mathrm{S} 1\left\{\begin{array}{l}
1: \mathrm{T} 1 \text { opened and } \mathrm{T} 4 \text { closed } \\
0: \mathrm{T} 1 \text { closed and } \mathrm{T} 4 \text { opended }
\end{array}\right. \\
& \mathrm{S} 2\left\{\begin{array}{l}
1: \mathrm{T} 2 \text { opened and } \mathrm{T} 2 \text { closed } \\
0: \mathrm{T} 5 \text { closed and } \mathrm{T} 5 \text { opened }
\end{array}\right. \\
& \text { S3 }\left\{\begin{array}{l}
1: \mathrm{T} 3 \text { opened and T6 closed } \\
0: \mathrm{T} 3 \text { closed and T6 opened }
\end{array}\right. \\
& \text { Either } \operatorname{Si}\left\{\begin{array}{l}
1: \text { Ti opened and } \mathrm{T}(\mathrm{i}+3) \text { closed } \\
0: \text { Ti closed and } \mathrm{T}(\mathrm{i}+3) \text { opened }
\end{array} \mathrm{i}=1,2,3\right.
\end{aligned}
$$

If $V_{1 M}, V_{2 M}$ and $V_{3 M}$ are the output voltages of each TSAF arm referred to the common point $\mathrm{M}$ of the arms and $V_{d c}$ is the voltage across the TSAF storage capacitor, then we can write:

$$
V_{i M}=S i * V_{d c}
$$


The modeling of the elements constituting the power part will facilitate the design of the control:

- Variable side of the TSAF

Consider the diagram in Figure 3; $V_{1 N}, V_{2 N}$ et $V_{3 N}$ are the voltages at the connection points of the TSAF, $I_{F 1}, I_{F 2}$ et $I_{F 3}$ are the currents generated by each arm of the TSAF, $V_{1 M}, V_{2 M}$ et $V_{3 M}$ are the output voltages of each TSAF arm referred to the common point $\mathrm{M}$ and $V_{M N}$ is the voltage between $\mathrm{M}$ and the neutral $(\mathrm{N})$ of the source. By applying the law of meshes on phases 1,2 and 3, we obtain the system of Equation (4).

$$
\left\{\begin{array}{l}
V_{1 N}=L_{f} \frac{\mathrm{d} I_{F 1}}{\mathrm{~d} t}+R_{f} I_{F 1}+V_{1 M}+V_{M N} \\
V_{2 N}=L_{f} \frac{\mathrm{d} I_{F 2}}{\mathrm{~d} t}+R_{f} I_{F 1}+V_{2 M}+V_{M N} \\
V_{3 N}=L_{f} \frac{\mathrm{d} I_{F 3}}{\mathrm{~d} t}+R_{f} I_{F 1}+V_{3 M}+V_{M N}
\end{array}\right.
$$

With $i=1,2,3$.

The system studied is a balanced three-phase system without zero sequence current, then:

$$
V_{1 N}+V_{2 N}+V_{3 N}=0 \text { and } I_{F 1}+I_{F 2}+I_{F 3}=0,
$$

By summing the three equations of the system of Equation (4), we will obtain Equation (6) giving the relation between $V_{M N}$ and $V_{i M}{ }^{\prime} s \quad(i=1,2,4)$.

$$
V_{M N}=-\frac{1}{3} \sum_{i=1}^{3} V_{i M}
$$

Now according to the Equation (2) we have $V_{i M}=S i * V_{d c}$, considering Equation (5) we can then write Equation (6):

$$
V_{M N}=-\frac{1}{3} \sum_{i=1}^{3} S i * V_{d c}
$$

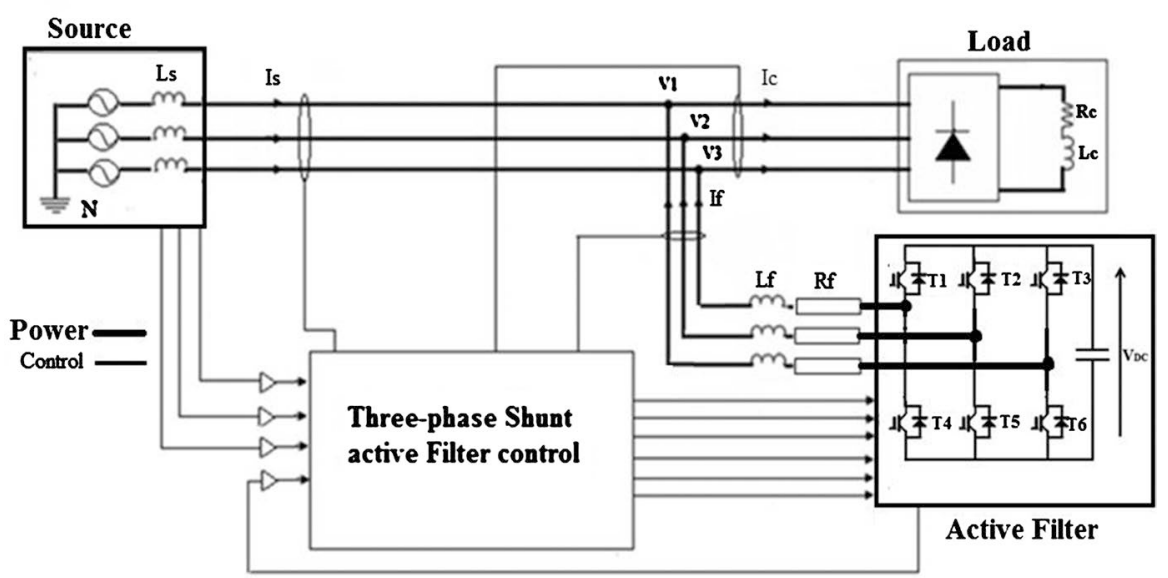

Figure 3. General structure of an active shunt filter. 
Taking into account of Equation (3) and Equation (7) we obtain Equation (8):

$$
\begin{gathered}
V_{i N}=L_{f} \frac{\mathrm{d} I_{F i}}{\mathrm{~d} t}+R_{f} I_{F i}+S i * V_{d c}-\frac{1}{3} \sum_{i=1}^{3} S i * V_{d c} \\
V_{i N}=L_{f} \frac{\mathrm{d} I_{F i}}{\mathrm{~d} t}+R_{f} I_{F i}+\left(S i-\frac{1}{3} \sum_{i=1}^{3} S i\right) * V_{d c} \\
\frac{\mathrm{d} I_{F i}}{\mathrm{~d} t}=\frac{V_{i N}}{L_{f}}-\frac{R_{f}}{L_{f}} I_{F i}-\frac{1}{L_{f}}\left(S i-\frac{1}{3} \sum_{i=1}^{3} S i\right) * V_{d c}
\end{gathered}
$$

Let us define by $V_{f i}$ the output voltages of the filter referred to the neutral, we have:

$$
V_{f i}=\left(S i-\frac{1}{3} \sum_{i=1}^{3} S i\right) * V_{d c}=K_{n i} * V_{d c}
$$

With $K_{n i}=\left(S i-\frac{1}{3} \sum_{i=1}^{3} S i\right)_{n}$

It can be noticed that $\sum_{i=1}^{3} K_{n i}=0$

The mathematical system governing the currents of the active shunt filter is given by the relation (10)

$$
\frac{\mathrm{d}}{\mathrm{d} t}\left(\begin{array}{l}
I_{F 1} \\
I_{F 2} \\
I_{F 3}
\end{array}\right)=-\frac{R_{f}}{L_{f}}\left[\begin{array}{lll}
1 & 0 & 0 \\
0 & 1 & 0 \\
0 & 0 & 1
\end{array}\right]\left(\begin{array}{l}
I_{F 1} \\
I_{F 2} \\
I_{F 3}
\end{array}\right)-\frac{V_{d c}}{L_{f}}\left(\begin{array}{l}
K_{n 1} \\
K_{n 2} \\
K_{n 3}
\end{array}\right)+\frac{1}{L_{f}}\left(\begin{array}{l}
V_{N 1} \\
V_{N 2} \\
V_{N 3}
\end{array}\right)
$$

With two switches for each of the three inverter arms of the TSAF there are then eight possible sequences for the voltage $V_{f i}$, the sequential function $K_{n i}$ depends not only on the sequence number $n=0,1,2, \cdots, 7$ but also on the phase number $i=1,2,3$. Thus, eight possible cases of output voltage of the active filter $V_{f i}$ referred to neutral can be expressed in Table 1 [3] [9].

Let us consider $\mathrm{d} Q_{c}$ as the amount of charge stored in the capacitor during a time interval $\mathrm{d} t, i_{c}$ the current flowing in the capacitor:

$$
\begin{gathered}
\mathrm{d} Q_{c}=i_{c} \mathrm{~d} t=C_{d} V_{d c} \text { from which } \\
\frac{\mathrm{d} V_{d c}}{\mathrm{~d} t}=\frac{i_{c}}{C}
\end{gathered}
$$

Table 1. Possible output voltages of the active filter.

\begin{tabular}{ccccccc}
\hline $\mathrm{n}$ & $\mathrm{S} 3$ & $\mathrm{~S} 2$ & $\mathrm{~S} 1$ & $\mathrm{Vf} 1$ & $\mathrm{Vf} 2$ & $\mathrm{Vf} 3$ \\
\hline 0 & 0 & 0 & 0 & 0 & 0 & 0 \\
1 & 0 & 0 & 1 & $-\mathrm{VDC} / 3$ & $-\mathrm{VDC} / 3$ & $2 \mathrm{VDC} / 3$ \\
2 & 0 & 1 & 0 & $-\mathrm{VDC} / 3$ & $2 \mathrm{VDC} / 3$ & $-\mathrm{VDC} / 3$ \\
3 & 0 & 1 & 1 & $-2 \mathrm{VDC} / 3$ & $\mathrm{VDC} / 3$ & $\mathrm{VDC} / 3$ \\
4 & 1 & 0 & 0 & $2 \mathrm{VDC} / 3$ & $-\mathrm{VDC} / 3$ & $-\mathrm{VDC} / 3$ \\
5 & 1 & 0 & 1 & $-\mathrm{VDC} / 3$ & $2 \mathrm{VDC} / 3$ & $-\mathrm{VDC} / 3$ \\
6 & 1 & 1 & 0 & $\mathrm{VDC} / 3$ & $\mathrm{VDC} / 3$ & $-2 \mathrm{VDC} / 3$ \\
7 & 1 & 1 & 1 & 0 & 0 & 0
\end{tabular}


By applying the law of nodes, we will have:

$i_{c}=S 1 * I_{F 1}+S 2 * I_{F 2}+S 3 * I_{F 3}$, we can then write $i_{c}=\sum_{i=1}^{3} S i * I_{F i}$, it is also verifiable that $\sum_{i=1}^{3} S i * I_{F i}=\sum_{i=1}^{3} K_{n i} * I_{F i}$.

The Equation (11) then becomes:

$$
\frac{\mathrm{d} V_{d c}}{\mathrm{~d} t}=\frac{1}{C} \sum_{i=1}^{3} S i * I_{F i}=\frac{1}{C} \sum_{i=1}^{3} K_{n i} * I_{F i}
$$

Taking into account the absence of the homo-polar sequence in the current system $\left(\sum_{i=1}^{3} I_{F i}=0\right)$ and the fact that $\sum_{i=1}^{3} K_{n i}=0$, we can then write:

$I_{F 3}=-I_{F 1}-I_{F 2}$ and $K_{n 3}=-K_{n 1}-K_{n 2}$; we can write the differential equation of the continuous side:

$$
\begin{gathered}
\frac{\mathrm{d} V_{d c}}{\mathrm{~d} t}=\frac{1}{C}\left(K_{n 1} * I_{F 1}+K_{n 2} * I_{F 2}+K_{n 3} * I_{F 3}\right) \\
\frac{\mathrm{d} V_{d c}}{\mathrm{~d} t}=\frac{1}{C}\left(2 K_{n 1} * I_{F 1}+2 K_{n 2} * I_{F 2}+K_{n 1} * I_{F 2}+K_{n 2} * I_{F 1}\right) \\
\frac{\mathrm{d} V_{d c}}{\mathrm{~d} t}=\frac{1}{C}\left(2 K_{n 1}+K_{n 2}\right) I_{F 1}+\frac{1}{C}\left(2 K_{n 2}+K_{n 1}\right) I_{F 2} \\
\left\{\begin{array}{l}
\frac{\mathrm{d} I_{F 1}}{\mathrm{~d} t}=\frac{V_{1 N}}{L_{f}}-\frac{R_{f}}{L_{f}} I_{F 1}-\frac{K_{n 1}}{L_{f}} V_{d c} \\
\frac{\mathrm{d} I_{F 2}}{\mathrm{~d} t}=\frac{V_{2 N}}{L_{f}}-\frac{R_{f}}{L_{f}} I_{F 2}-\frac{K_{n 2}}{L_{f}} V_{d c} \\
\frac{\mathrm{d} V_{d c}}{\mathrm{~d} t}=\frac{1}{C}\left(2 K_{n 1}+K_{n 2}\right) I_{F 1}+\frac{1}{C}\left(2 K_{n 2}+K_{n 1}\right) I_{F 2}
\end{array}\right.
\end{gathered}
$$

Either in matrix form:

$$
\frac{\mathrm{d}}{\mathrm{d} t}\left(\begin{array}{c}
I_{F 1} \\
I_{F 2} \\
V_{d c}
\end{array}\right)=\left[\begin{array}{ccc}
-\frac{R_{f}}{L_{f}} & 0 & -\frac{K_{n 1}}{L_{f}} \\
0 & -\frac{R_{f}}{L_{f}} & -\frac{K_{n 2}}{L_{f}} \\
\frac{1}{C}\left(2 K_{n 1}+K_{n 2}\right) & \frac{1}{C}\left(2 K_{n 2}+K_{n 1}\right) & 0
\end{array}\right]\left(\begin{array}{c}
I_{F 1} \\
I_{F 2} \\
V_{d c}
\end{array}\right)+\frac{1}{L_{f}}\left[\begin{array}{c}
V_{1 N} \\
V_{2 N} \\
0
\end{array}\right]
$$

Notice that this model is a minimal representation in the state space. They are variable in time and non-linear [8] [10].

In the following paragraphs, the two methods, linear and non-linear, will be proposed for the determination of the reference currents of the first step of the TSAF control then the pulse width modulation control will be used for the control of the TSAF inverter switches.

\subsection{Linear Three-Phase Shunt Active Filter Control}

For the linear control of the three-phase active shunt filter it will be applied d-q transformation method, without implication of the TSAF current for the search of the disturbing currents. This makes the method linear and approximates [8]. 
The method of detection of disturbance currents by synchronous reference frame or d-q transformation method is a method applicable as well to balanced three-phase systems as to neutral and/or unbalanced three-phase systems. It is based on instantaneous values, hence a good dynamic response time. It consists in transforming the 1-2-3 coordinates of the non-linear load current into $\mathrm{d}-\mathrm{q}$ coordinates using the Park transform $P_{32}$ (18) by setting the frequency of the latter in synchronism with that of the network [3] [4].

The Park transform synchronized with the grid frequency has the effect of transforming the fundamental current component into a DC component while the harmonic current components undergo a shift in the frequency spectrum. The elimination of the DC component is achieved by adding a high-pass filter (HPF). The reference current is obtained by Park reverse transformation $P_{23}$ (19).

The algorithm for calculating reference currents using the synchronous reference method is given in Figure 4.

Let $\left[I_{c(123)}\right],\left[I_{c(d q)}\right],\left[P_{32}\right]$ and $\left[P_{23}\right]$ be the non-linear load current vector in reference frame $1-2-3$, in reference frame $\mathrm{d}-\mathrm{q}$, the Park transform and the Park inverse transform, respectively.

$$
\begin{gathered}
{\left[I_{c(123)}\right]=\left[\begin{array}{c}
I_{c 1} \\
I_{c 2} \\
I_{c 3}
\end{array}\right]} \\
{\left[I_{c(d q)}\right]=\left[\begin{array}{c}
I_{c d} \\
I_{c q}
\end{array}\right]} \\
{\left[P_{32}\right]=\frac{2}{3}\left[\begin{array}{ccc}
\sin (\omega t) & \sin (\omega t-2 \pi / 3) & \sin (\omega t+2 \pi / 3) \\
\cos (\omega t) & \cos (\omega t-2 \pi / 3) & \cos (\omega t+2 \pi / 3) \\
1 / 2 & 1 / 2 & 1 / 2
\end{array}\right]} \\
{\left[P_{23}\right]=\frac{2}{3}\left[\begin{array}{ccc}
\sin (\omega t) & \cos (\omega t) & 1 \\
\sin (\omega t-2 \pi / 3) & \cos (\omega t-2 \pi / 3) & 1 \\
\sin (\omega t+2 \pi / 3) & \cos (\omega t+2 \pi / 3) & 1
\end{array}\right]}
\end{gathered}
$$

It should be noticed that $\left[P_{23}\right]=\left[P_{23}\right]^{\mathrm{T}}=\left[P_{23}\right]^{-1}$

The passage of the current vector from reference frame 1-2-3 to reference frame d-q is given by the Equation (20) and the calculation of the reference currents by the Equation (21).

$$
\left[I_{c(d q)}\right]=\left[P_{32}\right]\left[I_{c(123)}\right]
$$

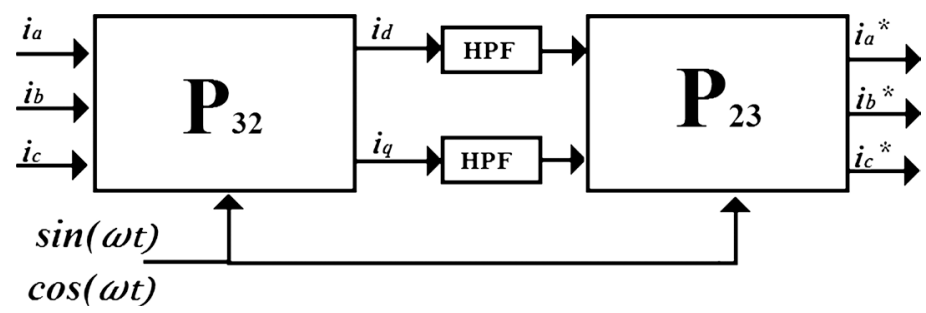

Figure 4. Linear control detection algorithm. 


$$
\left[I_{c(123)}^{*}\right]=\left[P_{23}\right]\left[I_{c(d q)}\right]
$$

$\left[I_{c(123)}^{*}\right]$ being the reference current vector.

Linear control models are generally approximate models. In the following paragraph we will study the non-linear control of the TSAF with a view to a comparison with the studies carried out upstream.

\subsection{Non-Linear Three-Phase Shunt Active Filter Control}

Linear control models are generally approximate models. For a model closer to the real system, it is more interesting to apply a non-linear command. There are several non-linear control approaches [8] [10]. The one used in this paragraph is based on the decoupling and linearization of the equations governing the system modeled above. Thus, it will be carried out a transformation of the base 3 to the base 2 by the Park transformation of the currents of the active shunt filter.

Let us find again the system of Equations (10) resulting from the modeling of the active shunt filter in the $\mathrm{d}-\mathrm{q}$ reference frame. Let us write the relations allowing the passage from base $2(\mathrm{~d}, \mathrm{q})$ to base $3(1,2,3)$ of the current vector of the active shunt filter, the sequential function vector $K_{n i}$, the voltage vector at the connection point $V_{i N}$ and the relation governing the dynamics of the currents of the active shunt filter:

$$
\begin{aligned}
& {\left[I_{F(123)}\right]=\left[P_{23}\right]\left[I_{F(d q)}\right],} \\
& {\left[K_{n(123)}\right]=\left[P_{23}\right]\left[K_{n(d q)}\right] \text {, }} \\
& {\left[V_{N(123)}\right]=\left[P_{23}\right]\left[V_{N(d q)}\right]} \\
& \frac{\mathrm{d}}{\mathrm{d} t}\left[I_{F(123)}\right]=-\frac{R_{f}}{L_{f}}\left[\begin{array}{ccc}
1 & 0 & 0 \\
0 & 1 & 0 \\
0 & 0 & 1
\end{array}\right]\left[I_{F(123)}\right]-\frac{V_{d c}}{L_{f}}\left[K_{n(123)}\right]+\frac{1}{L_{f}}\left[V_{N(123)}\right]
\end{aligned}
$$

You can then write:

$$
\begin{aligned}
\frac{\mathrm{d}}{\mathrm{d} t}\left[P_{23}\right]\left[I_{F(d q)}\right]= & -\frac{R_{f}}{L_{f}}\left[\begin{array}{lll}
1 & 0 & 0 \\
0 & 1 & 0 \\
0 & 0 & 1
\end{array}\right]\left[I_{F(d q)}\right]-\frac{V_{d c}}{L_{f}}\left[P_{23}\right]\left[K_{n(d q)}\right] \\
& +\frac{1}{L_{f}}\left[P_{23}\right]\left[V_{N(d q)}\right]
\end{aligned}
$$

But

$$
\begin{aligned}
& \frac{\mathrm{d}}{\mathrm{d} t}\left[P_{23}\right]\left[I_{F(d q)}\right]=\left[I_{F(d q)}\right] \frac{\mathrm{d}}{\mathrm{d} t}\left[P_{23}\right]+\left[P_{23}\right] \frac{\mathrm{d}}{\mathrm{d} t}\left[I_{F(d q)}\right] \\
& \frac{\mathrm{d}}{\mathrm{d} t}\left[I_{F(d q)}\right]=\left(-\left[P_{32}\right] \frac{\mathrm{d}}{\mathrm{d} t}\left[P_{23}\right]-\frac{R_{f}}{L_{f}}\left[\begin{array}{lll}
1 & 0 & 0 \\
0 & 1 & 0 \\
0 & 0 & 1
\end{array}\right]\right)\left[I_{F(d q)}\right] \\
&-\frac{V_{d c}}{L_{f}}\left[K_{n(d q)}\right]+\frac{1}{L_{f}}\left[V_{N(d q)}\right]
\end{aligned}
$$


and

$$
\left[P_{32}\right] \frac{\mathrm{d}}{\mathrm{d} t}\left[P_{23}\right]=\omega\left[P_{32}\right]\left[P_{23}\right]\left[\begin{array}{ccc}
0 & 1 & 0 \\
-1 & 1 & 0 \\
0 & 0 & 1
\end{array}\right]
$$

Hence the Equations (26) and (27) which govern the currents of the active shunt filter in the two-phase plane d-q:

$$
\begin{aligned}
\frac{\mathrm{d}}{\mathrm{d} t}\left[I_{F(d q)}\right]= & {\left[\begin{array}{ccc}
-\frac{R_{f}}{L_{f}} & \omega & 0 \\
-\omega & -\frac{R_{f}}{L_{f}} & 0 \\
0 & 0 & -\frac{R_{f}}{L_{f}}
\end{array}\right]\left[I_{F(d q)}\right]-\frac{V_{d c}}{L_{f}}\left[K_{n(d q)}\right]+\frac{1}{L_{f}}\left[V_{N(d q)}\right] } \\
& \left\{\begin{array}{l}
L_{f} \frac{\mathrm{d} I_{F d}}{\mathrm{~d} t}+R_{f} I_{F d}=L_{f} \omega I_{F q}-V_{d c} K_{n d}+V_{d N} \\
L_{f} \frac{\mathrm{d} I_{F q}}{\mathrm{~d} t}+R_{f} I_{F q}
\end{array}=-\omega I_{F d}-V_{d c} K_{n q}+V_{q N}\right.
\end{aligned}
$$

The Equation (28) of the continuous bus can also be rewritten in the two-phase plane d-q:

$$
\begin{aligned}
& \frac{\mathrm{d} V_{d c}}{\mathrm{~d} t}=\frac{1}{C}\left[\begin{array}{lll}
K_{n 1} & K_{n 2} & K_{n 3}
\end{array}\right]\left[\begin{array}{c}
I_{F 1} \\
I_{F 2} \\
I_{F 3}
\end{array}\right] \\
& \frac{\mathrm{d} V_{d c}}{\mathrm{~d} t}=\frac{1}{C}\left[\begin{array}{lll}
K_{n d} & K_{n q} & 0
\end{array}\right]\left[P_{32}\right]\left[P_{23}\right]\left[\begin{array}{c}
I_{F d} \\
I_{F q} \\
0
\end{array}\right] \\
& \frac{\mathrm{d} V_{d c}}{\mathrm{~d} t}=\frac{1}{C} K_{n d} I_{F d}+\frac{1}{C} K_{n d} I_{F d}
\end{aligned}
$$

The minimum representation in the state space can then be rewritten in the d-q plane:

$$
\begin{aligned}
& \int \frac{\mathrm{d} I_{F d}}{\mathrm{~d} t}=-\frac{R_{f}}{L_{f}} I_{F d}+\omega I_{F q}-\frac{V_{d c}}{L_{f}} K_{n d}+\frac{V_{d N}}{L_{f}} \\
& \left\{\frac{\mathrm{d} I_{F q}}{\mathrm{~d} t}=-\frac{R_{f}}{L_{f}} I_{F q}-\omega I_{F d}-\frac{V_{d c}}{L_{f}} K_{n q}+\frac{V_{q N}}{L_{f}}\right. \\
& \frac{\mathrm{d} V_{d c}}{\mathrm{~d} t}=\frac{1}{C} K_{n d} I_{F d}+\frac{1}{C} K_{n d} I_{F d} \\
& \frac{\mathrm{d}}{\mathrm{d} t}\left(\begin{array}{c}
I_{F d} \\
I_{F q} \\
V_{d c}
\end{array}\right)=\left[\begin{array}{ccc}
-\frac{R_{f}}{L_{f}} & \omega & 0 \\
-\omega & -\frac{R_{f}}{L_{f}} & 0 \\
0 & 0 & -\frac{R_{f}}{L_{f}}
\end{array}\right]\left(\begin{array}{c}
I_{F d} \\
I_{F q} \\
V_{d c}
\end{array}\right)+\left[\begin{array}{cc}
-\frac{V_{d c}}{L_{f}} & 0 \\
0 & -\frac{V_{d c}}{L_{f}} \\
\frac{I_{F d}}{C} & \frac{I_{F q}}{C}
\end{array}\right]\left(\begin{array}{c}
K_{N d} \\
K_{N q} \\
0
\end{array}\right)+\frac{1}{L_{f}}\left[\begin{array}{c}
V_{d N} \\
V_{q N} \\
0
\end{array}\right]
\end{aligned}
$$


If we consider the system of Equations (30) we will notice in the first two equations the presence of the current $I_{F d}$ in the differential equation containing the first derivative of the current $I_{F q}$ and vice versa. The third equation is characterized by the multiplication of the components of the sequential function vector by the DC bus voltage $V_{d c}$. The system is then coupled and non-linear.

To control the filter, the system of Equations (30) would have to be decoupled and linearized [8].

By introducing the new variables $\mathcal{E}_{d}$ and $\mathcal{E}_{q}$,

$$
\left\{\begin{array}{l}
\mathcal{E}_{d}=L_{f} \omega I_{F q}-V_{d c} K_{n d}+V_{d N} \\
\mathcal{E}_{q}=-\omega I_{F d}-V_{d c} K_{n q}+V_{q N}
\end{array}\right.
$$

The control law will be defined by $K_{n d}$ and $K_{n q}$ which after transformation from base 2 to base 3 , are directly linked to the generation of the control pulses of the active shunt filter by the relation

$$
\begin{gathered}
K_{n i}=\left(S i-\frac{1}{3} \sum_{i=1}^{3} S i\right)_{n} . \\
\left\{\begin{array}{l}
K_{n d}=\frac{V_{d N}+L_{f} \omega I_{F q}+\mathcal{E}_{d}}{V_{d c}} \\
K_{n q}=\frac{V_{q N}-L_{f} \omega I_{F d}+\mathcal{E}_{q}}{V_{d c}}
\end{array}\right.
\end{gathered}
$$

With

$$
\begin{aligned}
& \mathcal{E}_{d}=L_{f} \frac{\mathrm{d} I_{F d}}{\mathrm{~d} t}+R_{f} \\
& \mathcal{E}_{q}=L_{f} \frac{\mathrm{d} I_{F q}}{\mathrm{~d} t}+R_{f} I_{F q}
\end{aligned}
$$

Thus, the algorithm of non-linear control by the synchronous repository method is given in Figure 5.

\section{Simulation Results and Comparison}

\subsection{Simulation Results}

The general structure of the studied system shows in Figure 6 consists of a polluted

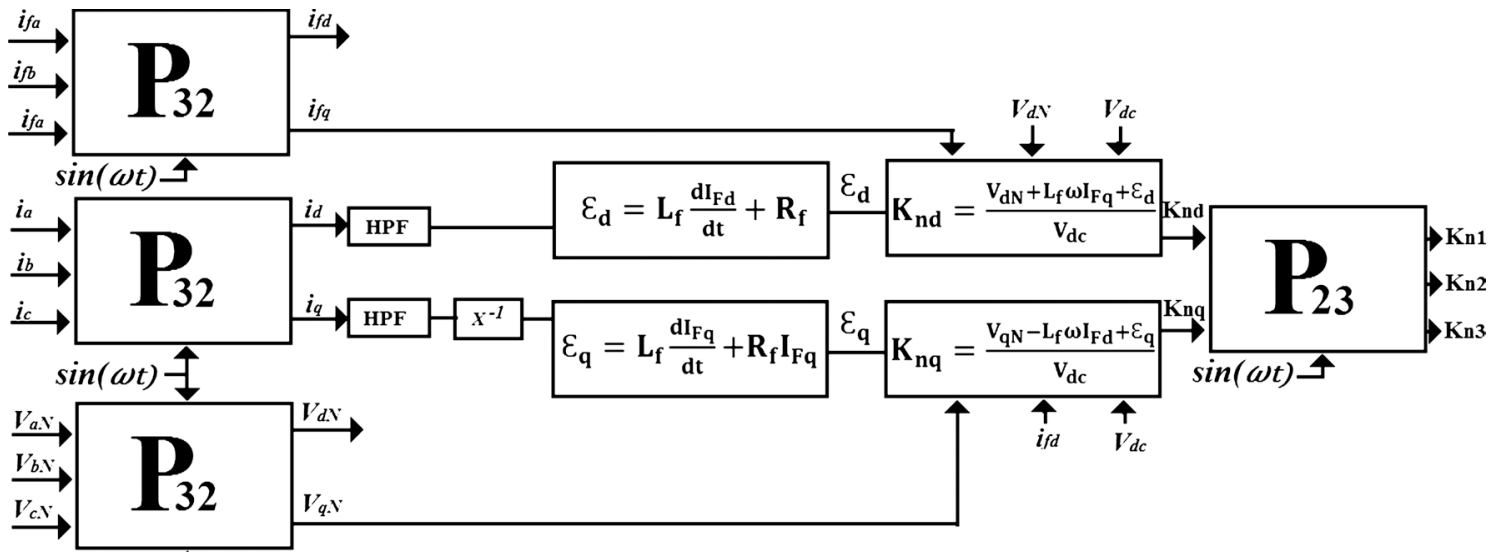

Figure 5. Algorithm of detection by non-linear control. 
three-phase power source supplying a non-linear load. The active three-phase shunt filter is connected in parallel to the mains in order to decontaminate it.

The power part is identical for both studies. Figure 7, Figure 8 and Figure 9 shows in the Matlab/Simulink environment the contents of the three-phase power supply blocks, the three-phase shunt active filter and the non-linear load, respectively. The common simulation parameters are given in Table 2 .

Since the control parts are different, the contents of the disturbance current detection blocks in linear and non-linear control can be seen in Figure 10 and Figure 11.
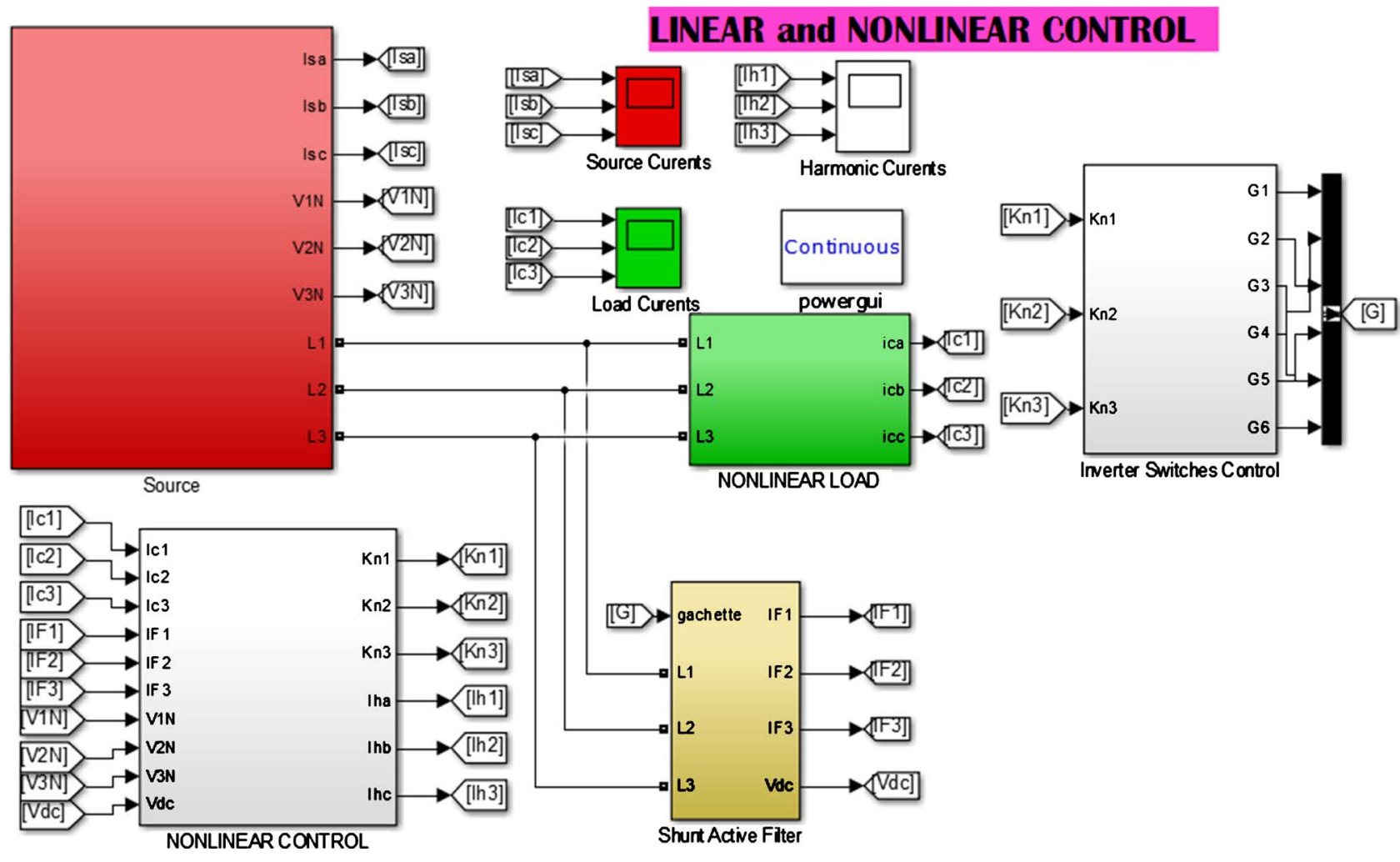

Figure 6. General structure of the system.

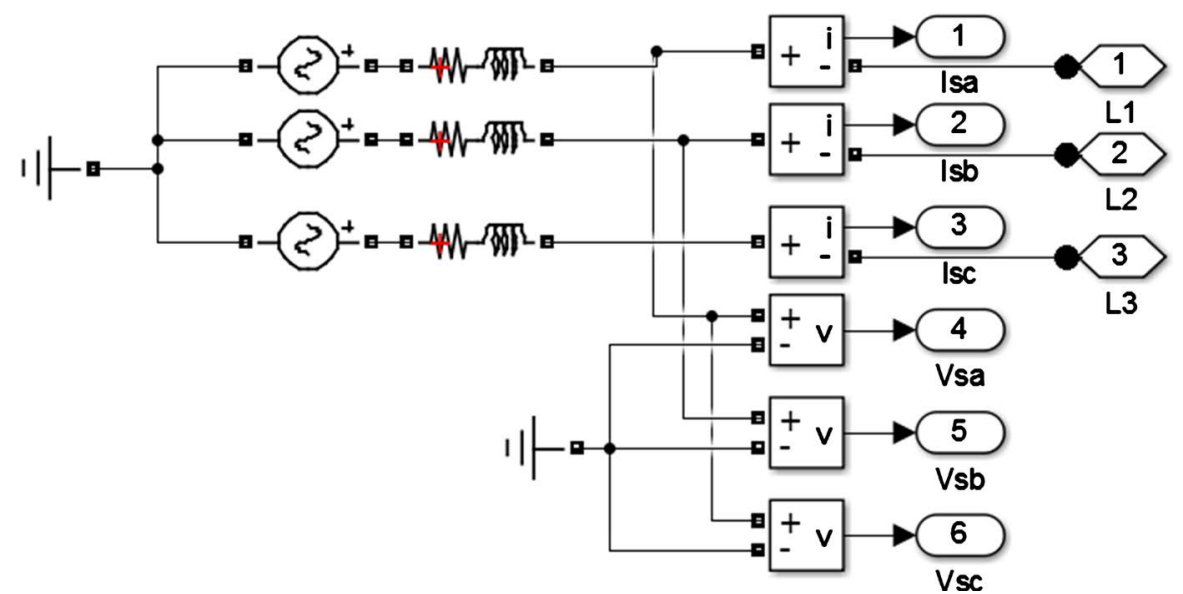

Figure 7. Structure of the three-phase power source. 


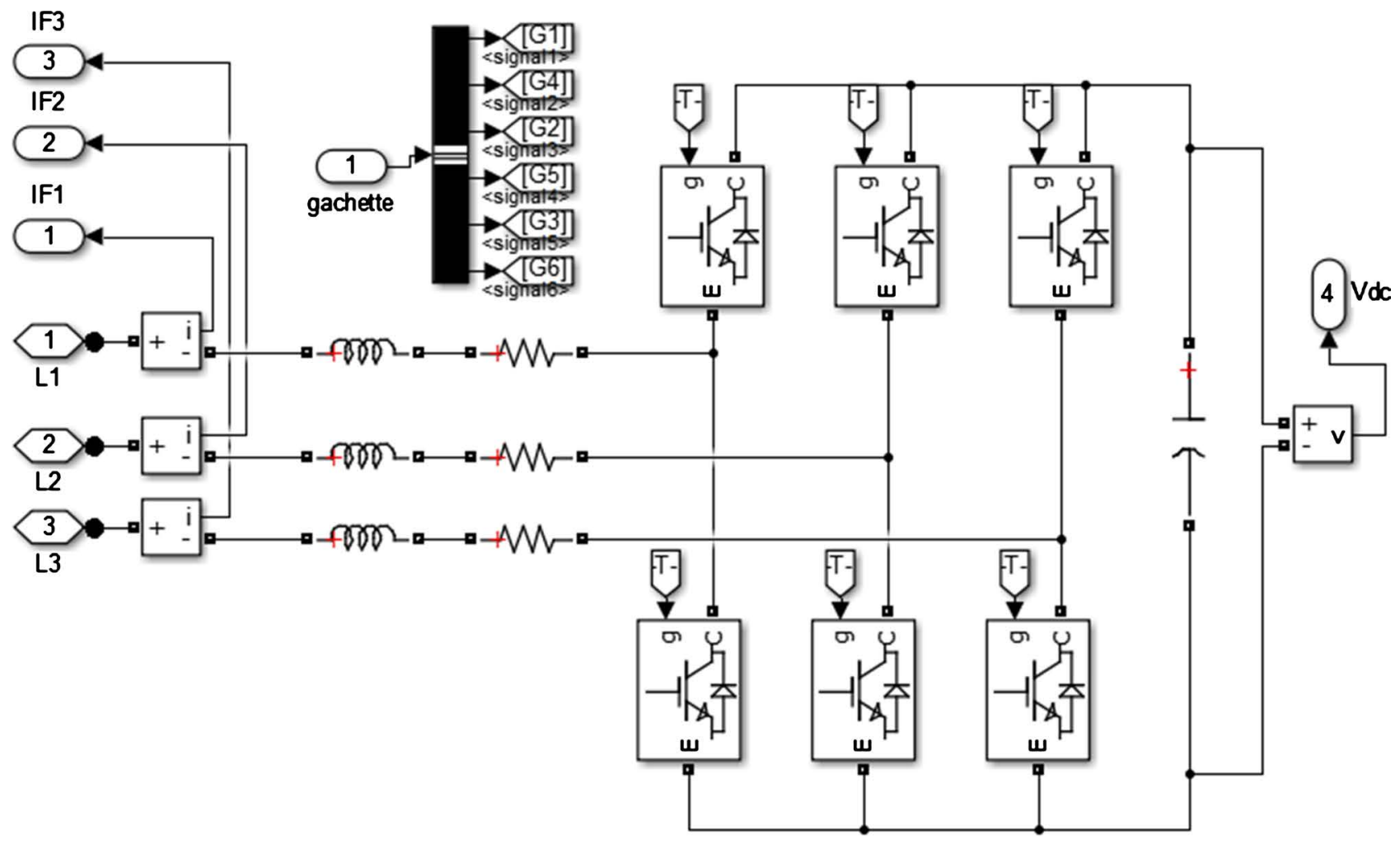

Figure 8. Three-phase shunt active filter.

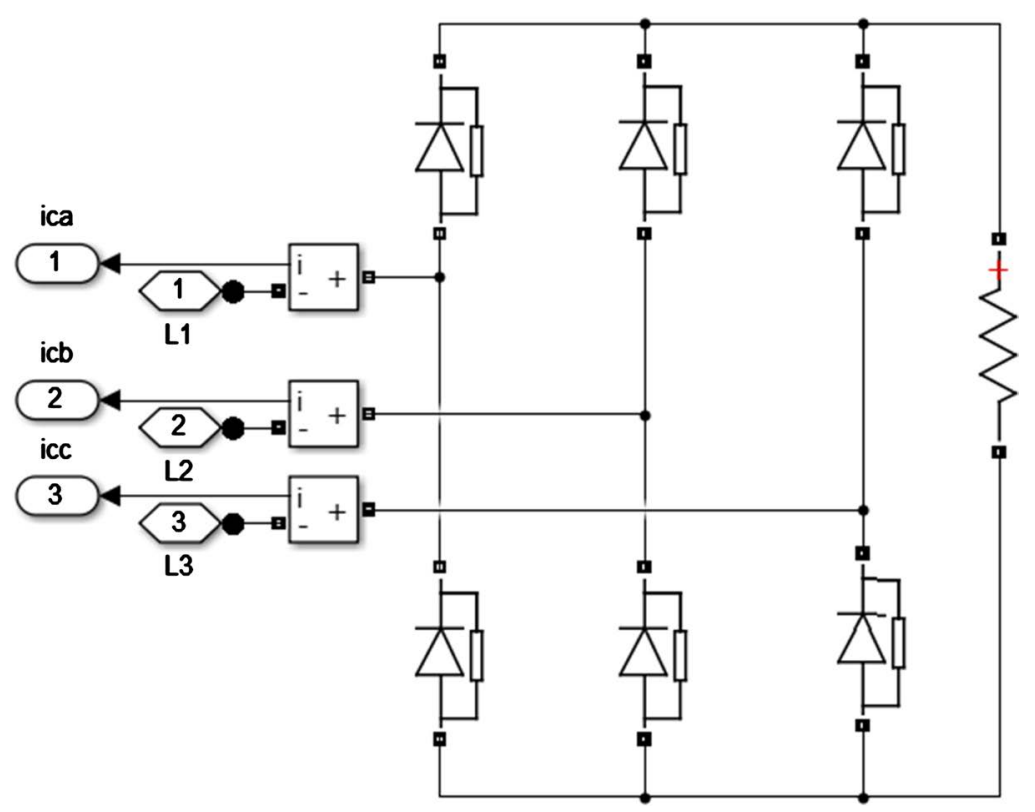

Figure 9. Structure of the three-phase non-linear load.

Table 2. Simulation parameters.

\begin{tabular}{cc}
\hline Source & $L_{s}=5 \times 10^{-5} \mathrm{H}, R_{s}=5 \Omega, V_{\text {eff }}=220 \mathrm{~V}$ \\
& $F=50 \mathrm{~Hz}, \varphi_{\mathrm{a}}=0, \varphi_{\mathrm{b}}=-2 \pi / 3 \varphi_{\mathrm{c}}=+2 \pi / 3$ \\
Load & $R_{c}=100 \Omega$ \\
TSAF & $L_{f}=6 \mathrm{mH} R_{f}=1 \Omega C_{d c}=2200 \mathrm{uF}$ \\
\hline
\end{tabular}




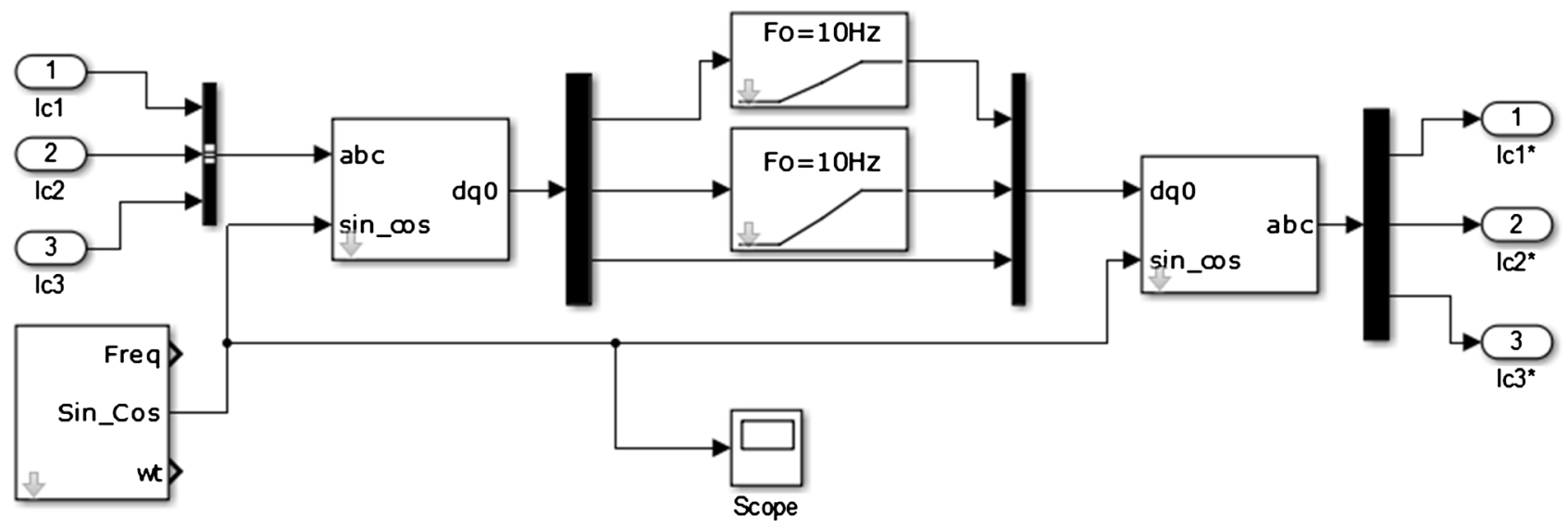

Figure 10. Detection of harmonic currents by the linear method.

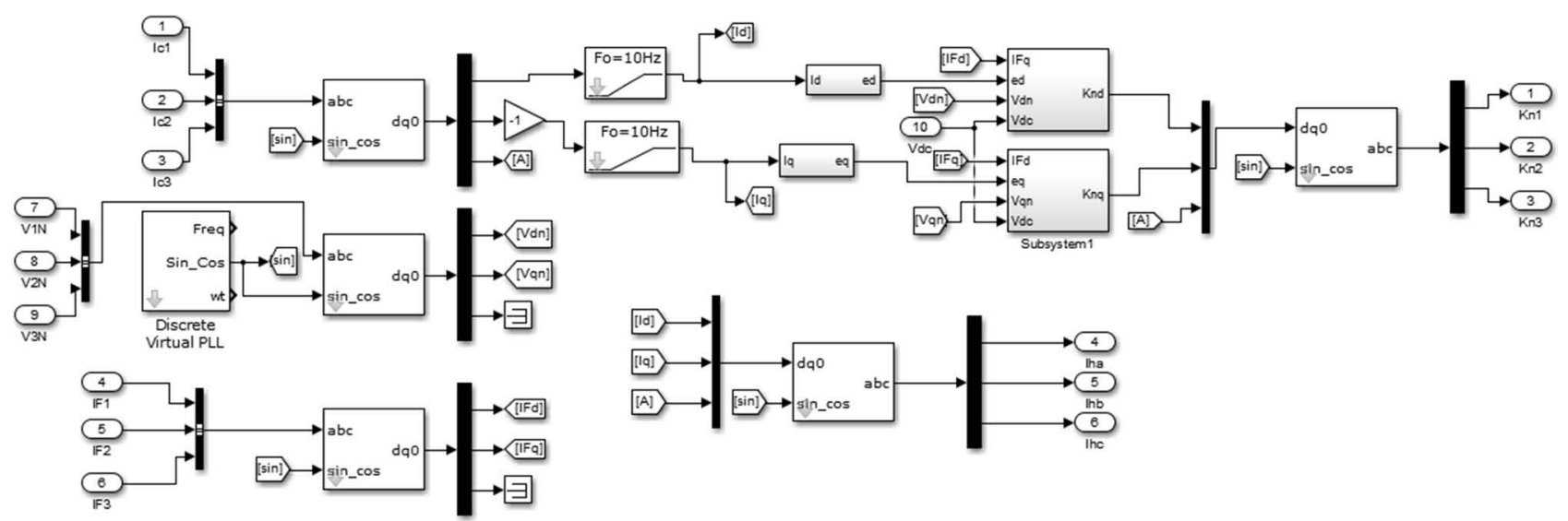

Figure 11. Detection of harmonic currents by the non-linear method.

The simulation results are given respectively for linear and non-linear control through Figure 12, Figure 13 and Figure 14, which first give the current waveforms and then the harmonic spectra before and after application of the TSAF.

\subsection{Comparison of Linear and Non-Linear Controls}

The comparison of the two control methods of the active shunt filters will be based on the simulation results: by comparison of the transient and permanent regimes, the waveforms of the output currents, the harmonic distortion rates, the stability of the system. For the same parameters, the harmonic distortion rate after application of the FAS is $1.46 \%$ for non-linear control against $1.44 \%$ for linear control. The variation in TDH is more significant in non-linear control $28.24 \%$ than in linear control $28.05 \%$.

Figure 12 shows that the waveforms of the output voltages $I_{s}(t)$ for both types of control became sinusoidal again after application of the active shunt filter. For both types of controls, the transitional regimes are short and stable as shown by the Figure 15 .

Table 3 provides a summary of the comparison of linear and non-linear FAST commands. 

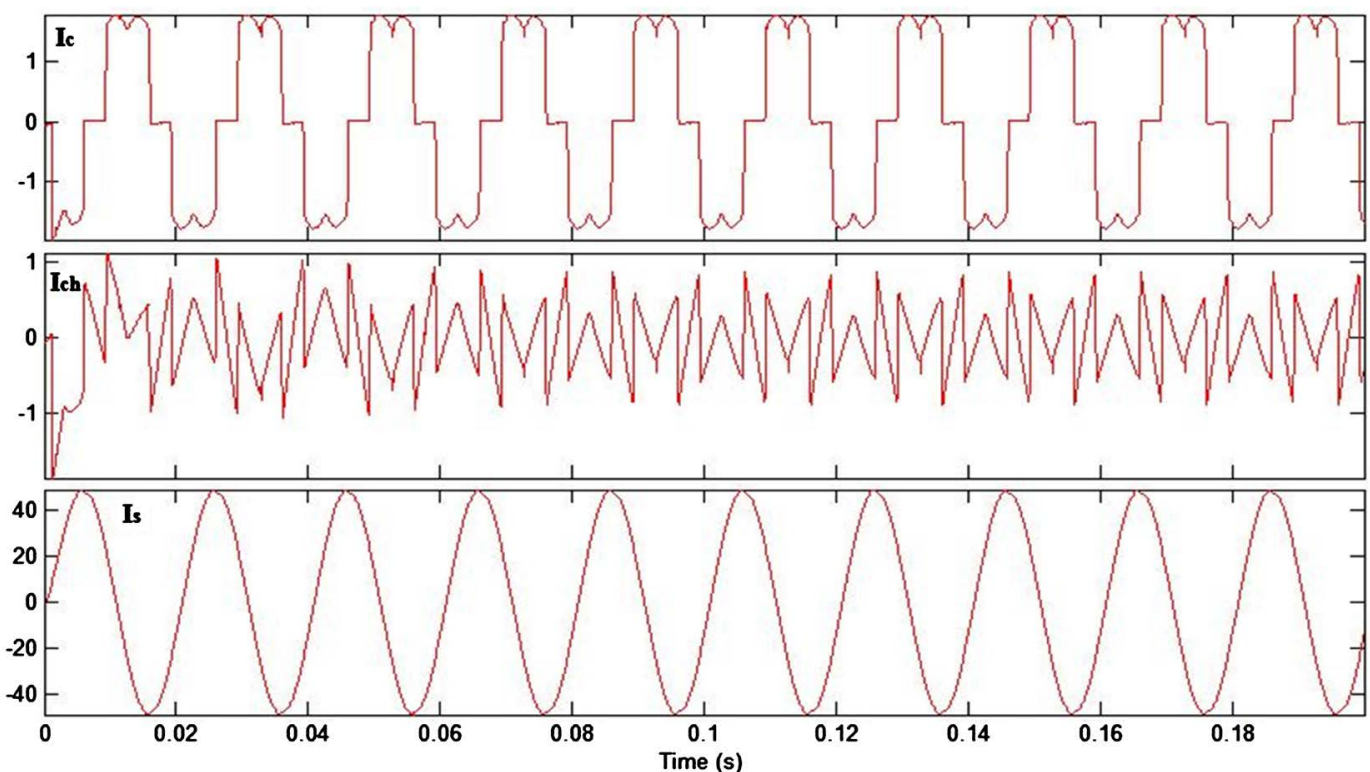

(a)
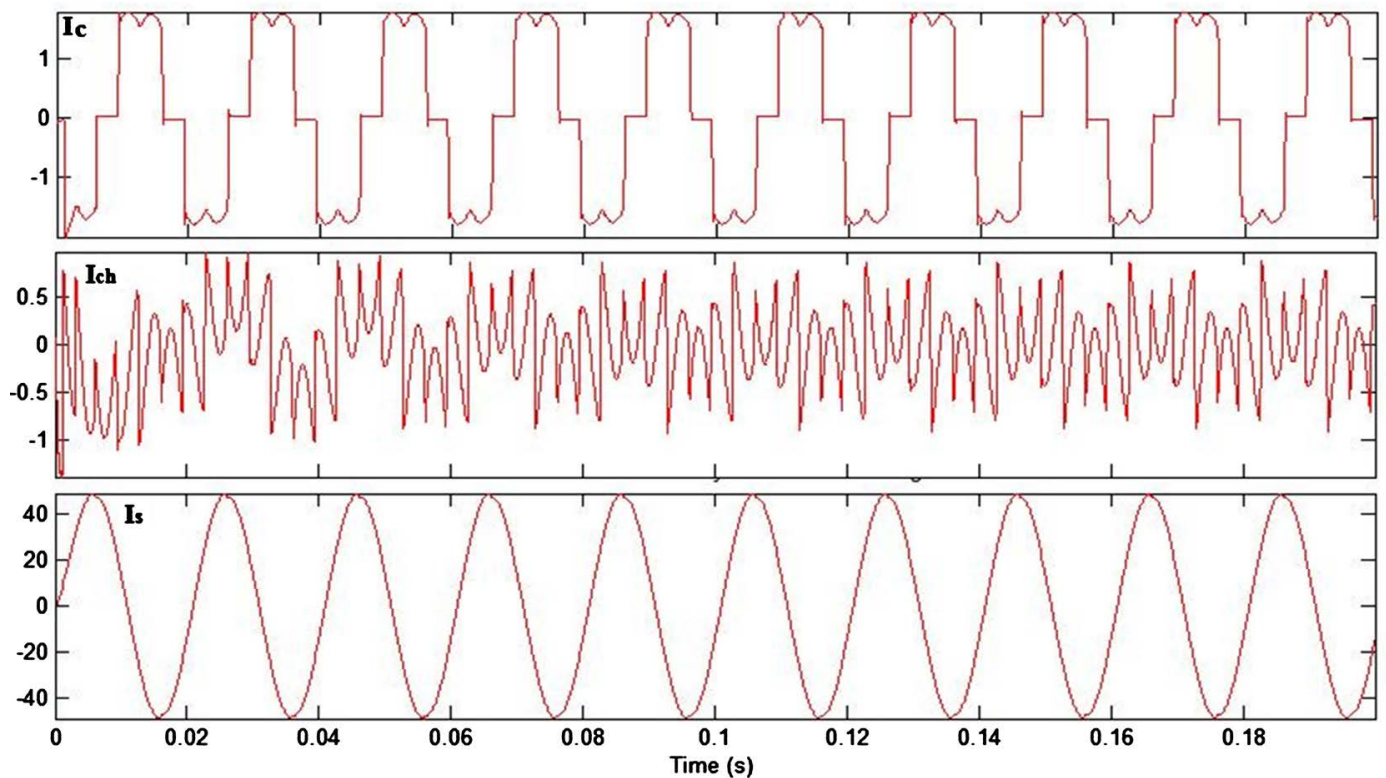

(b)

Figure 12. Waveform of load, harmonic and source currents. (a) Linear control; (b) non linear.

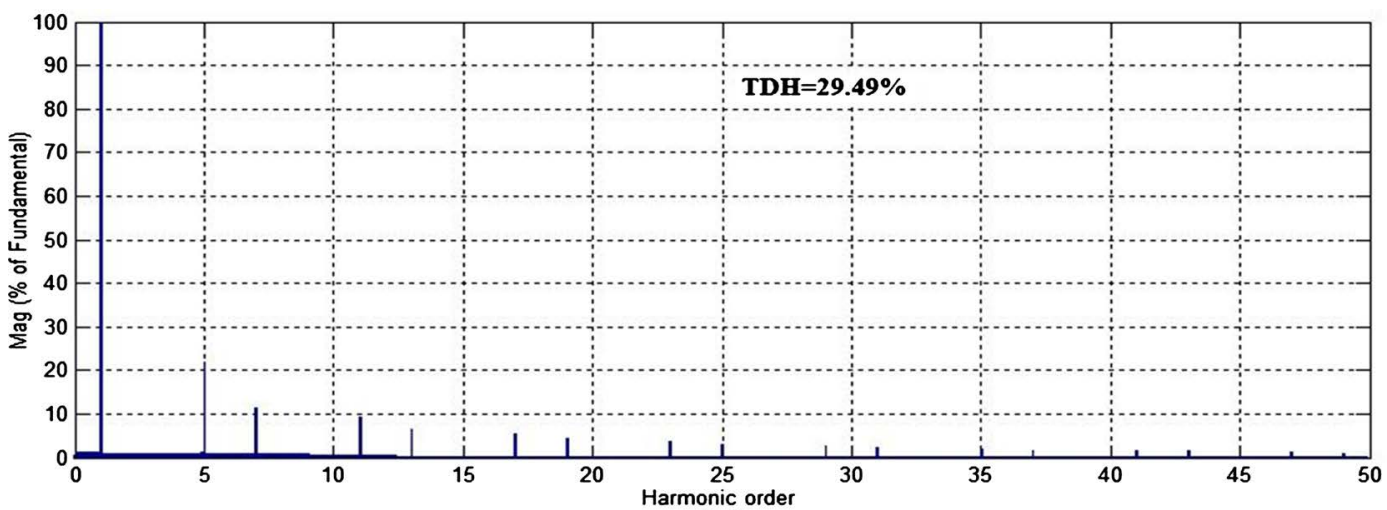

(a) 


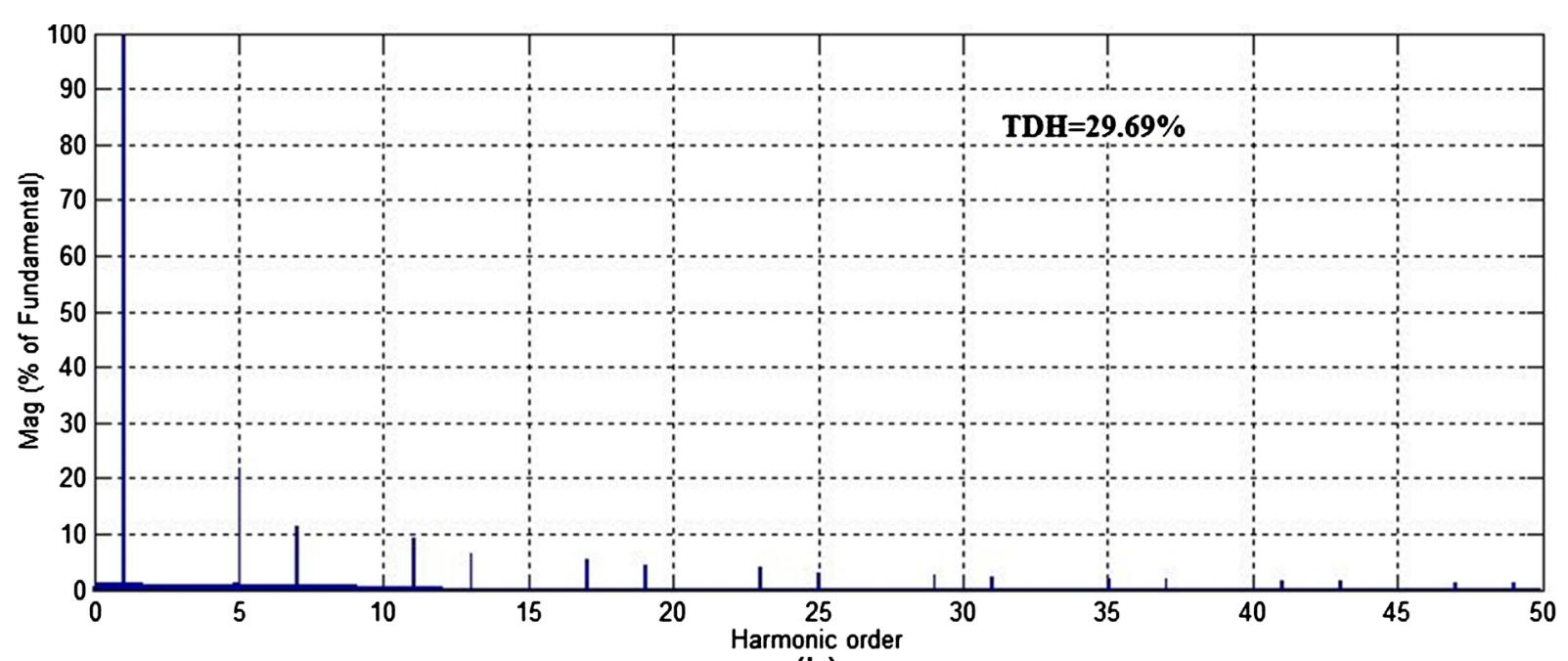

(b)

Figure 13. Order of source current harmonics and TDH before FAS action. (a) Linear control; (b) non linear.

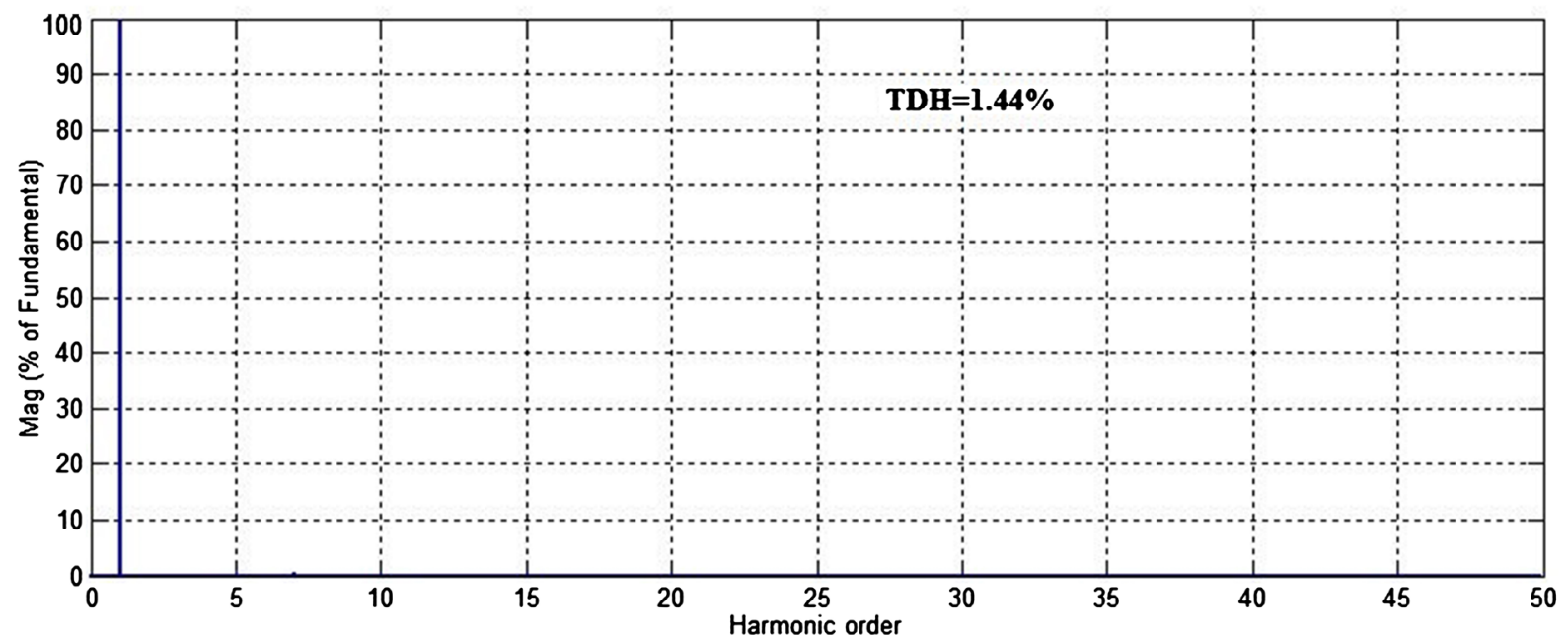

(a)

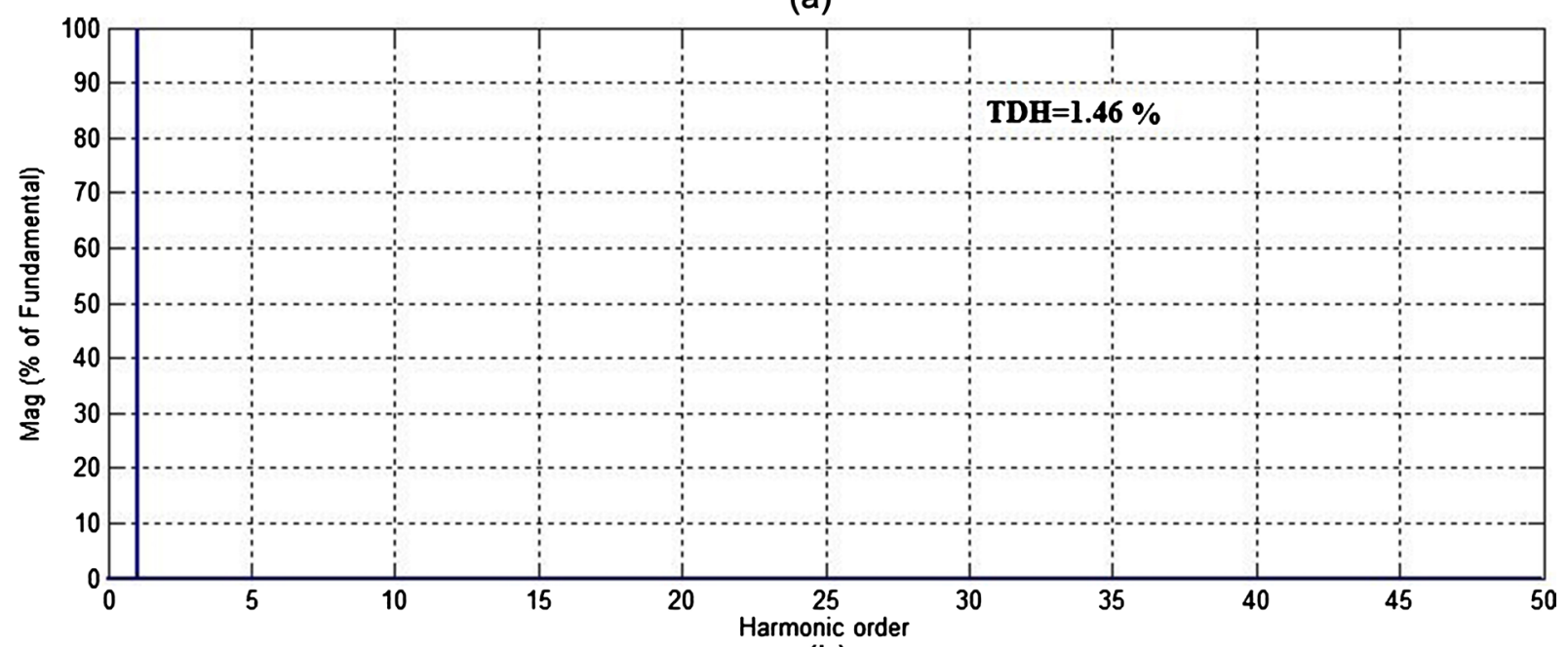

(b)

Figure 14. Order of source current harmonics and TDH after FAS action. (a) Linear control; (b) non linear. 

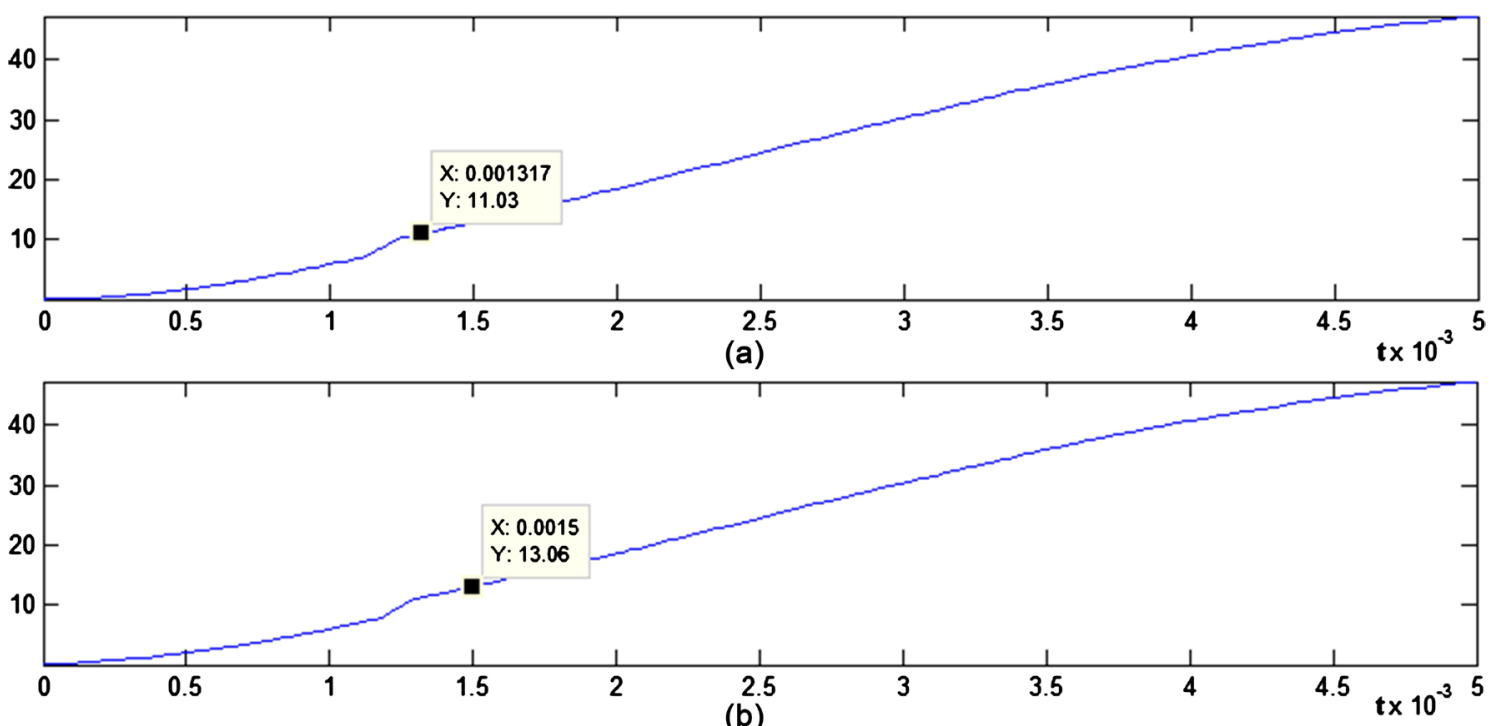

Figure 15. Transient regime. (a) Linear control; (b) non linear.

Table 3. Comparison of linear and non-linear controls.

\begin{tabular}{ccc}
\hline & Linear Control & Non-Linear control \\
\hline TDH before filtering & $29.49 \%$ & $29.69 \%$ \\
TDH after filtering & $1.44 \%$ & $1.46 \%$ \\
Variation of TDH & $28.05 \%$ & $25.23 \%$ \\
Transient regime & Good & Good \\
Permanent regime & Good & Good \\
\hline
\end{tabular}

\section{Conclusion}

Linear control models are generally approximate models. Hence, there is the need to explore non-linear models. Most real physics systems are modelled by non-linear equations or systems of equations. Non-linear control is best adopted to control the active filter which is a non-linear system. The compromises will then be the number calculated to raise to manage and above all a stability to maintain. The comparative study, by simulation, of the linear and non-linear controls of three-phase shunt active filters shows that although the non-linear control seems complex, for an improvement of the quality of electrical energy by active filtering, the latter is the best adopted last.

\section{Acknowledgements}

We acknowledge support from the African Center of Excellence MITIC of Gaston Berger University in Senegal.

\section{Conflicts of Interest}

The authors declare no conflicts of interest regarding the publication of this paper. 


\section{References}

[1] Gupta, S., Das, R.F. and Ashraful, B.C. (2016) A Comparative Study on Harmonics of Different Electric Bulbs. American Journal of Engineering Research (AJER), 5, 156-166.

[2] Abdoulkarimoun, D. (2018) Etudes des perturbations Harmonique et leurs traitements dans le réseau électrique: Cas du réseau BT de la ville de Niamey. $\mathrm{PhD}$ Thesis, Abdou Moumouni University, Niger.

[3] Mohamad, A.E.A. (2002) Contribution à l'Etude des Compensateurs Actifs des Réseaux Electriques Basse Tension. PhD Thesis, Louis Pasteur University, Strasbourg.

[4] Hind, D. (2007) Filtrage actif de puissance, PhD Thesis, Mentouri University, Constantine.

[5] Abdelhamid, H. (2010) Contribution à l'étude des filtres hybrides de puissance utilises pour améliorer la qualité de l'énergie dans le réseau électrique de distribution. PhD Thesis, Québec University, Canada.

[6] Shraddha, D., Jalaja, G.P.K., Manashri, Y. and Tuljapurkar, M.D. (2015) Detection of Harmonics in Distribution System Using FFT with Case Studies. International Journal for Scientific Research and Development, 3, 481-484.

[7] Antoni, H.N. (2017) Commande de filtres actifs parallèles sur un réseau fortement perturbé. PhD Thesis, Toulouse University, France.

[8] Sina, S. (2002) Etude d'une commande nonlinéaire sur un filtre actif. PhD Thesis, Québec University, Canada.

[9] Mohamed, M. (2007) Validation des techniques de commande d'un filtre actif parallèle. PhD Thesis, Québec University, Canada.

[10] Slotine, J.-J. and Li, W.P. (1991) Applied Nonlinear Control. Prentice Hall, Upper Saddle River. 